\title{
Cyclists as the element that creates the city
}

\author{
Katarzyna Szmygin \\ PhD student at the Faculty of Architecture Warsaw University of Technology, \\ Department of Urban Design and Rural Landscape, e-mail: szmygin.katarzyna@gmail.com
}

\begin{abstract}
The active participation of cyclists in the transformation of urban structures is becoming a commonly discussed subject nowadays. More bike lanes are being constructed, city bike stations, as well as grade-separated crossroads for cyclists and drivers are being created.Cyclists have been increasingly taken into consideration in the changes taking place within the city. Along with the revolution introduced by a Danish architect and urban planner Jan Gehl has changed thinking about cyclists. All of his regeneration and restoration projects focused primarily on structures that allow cyclists and pedestrians move without any obstacles. Article will discuss the founding of the cyclists-friendly city, the polish requirements for cycling infrastructure, as well as show examples of Polish and foreign properly designed solutions.
\end{abstract}

Keywords: Cyclists, city, bike paths, infrastructure, legislation.

\section{Introduction}

The bike as a mean of transport has accompanied humanity since the nineteenth century, when in 1818, Karl von Drais Freihher Sauerbronn patented the prototype of today's wheeler.

Over the next centuries, the vehicle has been converted into today's form. In an era in which the increasing emphasis is being put on environmental aspects, reducing carbon emissions and environmental protection, the bicycle became the alternative for fuelpowered vehicles. But what chances does the cyclist have on the road, if along with the improvement of the economic situation, more and more people in the world can afford to buy their own car (statistics prepared by the World Bank in 2014 show how many cars do 1,000 inhabitants have. The leader is San Marino - 1139 passenger cars per 1,000 inhabitants, Liechtenstein 744 vehicles per 1000 inhabitants and Monaco 729 cars per 1,000 citizens. According to the statistics in Poland there are 470 cars per 1,000 inhabitants, [1]). The question therefore arises whether, given those statistics, the cyclists are the users, for which the city should provide conditions of the free movement.

\section{Cyclists in the city - rights, duties, statistics}

The term 'bicycle', according to the Road Traffic Law [2], means the vehicle that is not exceeding $9 \mathrm{dm}$ wide and is being moved by muscle, which shall be equipped with the electric drive.

Quoted Act imposes a number of restrictions for people moving around on bicycles. As a full-fledged participant of the traffic he should be using a specially designated lanes or bike paths. In the absence of the above, the cyclist is obliged to navigate the road. In special cases (unfavorable weather conditions, lack of separate bike paths along the highways) 
cyclist can move on sidewalks or separated pedestrian paths with the proviso that pedestrians, as its legitimate users are given the priority.

These records show that in case there are no cycle paths (those in urban areas are becoming increasingly frequent, but still users complain about both quantity and quality) people riding bikes are forced to use roads intended for cars or sidewalks. This situation often creates a threat to every traffic participant. Motorists are complaining about cyclists who are moving at a low speed, pedestrians who have to watch out for speeding bikes and finally cyclists that either are moving right next to speeding cars or pedestrians they must evade.

The Centre of Social Opinion Research in 2012 has carried out the survey that shows that $70 \%$ of Poles are using the bicycle - for recreation, health, and also as a primary mean of communication [3]. Confronting such an obvious statistical data, cycle investments seem to be reasonable. However, the situation in Poland still does not correspond to European standards (European capitals can boast about thousands of kilometers completed bicycle paths). When it comes to the number of kilometers of bike roads in the city the Polish leader is Warsaw $-457 \mathrm{~km}$. The second place takes Wroclaw - 214, the third Gdansk - 185 [4]. Unfortunately, this amount of infrastructure still puts Poland at the lowest position in the European rankings.

\section{Polish legislation and cyclists}

Laws concerning the design and requirements of cycling paths can be found in the Ordinance of the Minister of Infrastructure and Maritime Economy of 2 March 1999 [5]. However, devoted to the issues of bicycle Chapter 9 'Bike paths' says only about the required widths:

- 1.5 meters, the bike path is one-way,

- 2.0 meter in case of bi-directional paths,

- 2.5 meters, when the one-way path can be used by pedestrians [6],

as well as the inclination:

- the longitudinal inclination should not exceed 5\%

- the transverse inclination should be single-sided and may be from $1 \%$ to $3 \%$ [7].

Users of the paths must adhere to the provisions contained in the Law on Road Traffic Law of 20 June 1997, which were discussed in the previous chapter.

Moreover, the City Council in major Polish cities, while preparing strategic documents began to include an obligation of building cyclist paths during major road repairs, if such investment is possible. Unfortunately, in this case the law is often being interpreted to the disadvantage of wheelers users due to small amount of legislation and their incorrect statement. This state of affairs leads to a slowdown in the planning of safe cycling infrastructure.

Another records, both direct and indirect, for cyclists and bicycle paths can be found in the Regulation of Minister of Infrastructure and Internal Affairs and Administration dated 31 July 2002 on road signs and signals [8] as well as in the Regulation of the Minister of Infrastructure of 3 July 2003 on specific technical conditions for road signs and signals and road traffic safety equipment and conditions of their placement on the road [9].

The examples of signs for the cyclists are outlined below in Fig.1. 
a

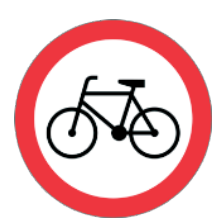

$\mathrm{b}$

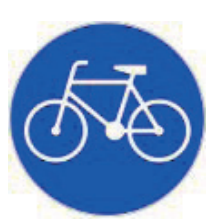

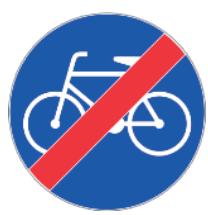

Fig. 1. a - sign B-9 "Prohibitory sign. No bicycles"; b - sign C-13 "Bicycle route", c - sign C-13a "End of route" [10]

\section{The idea of a cyclist-friendly city}

Thinking about the cyclist-friendly city is being attributed to Jan Gehl (Jan Gehl was born on September 17 1936. He is a Danish architect and urban planner, Professor of School of Architecture at the Royal Danish Academy of Fine Arts, the founder of Gehl Architects - Urban Quality Consultants. During work he focuses on the study of form and purpose public spaces and implements this knowledge into projects in order to redesign the space. Great emphasis is placed on the importance of cyclists and pedestrians in the city. According to Gehl those are the main users of the city. It aims to reduce car traffic in the city, especially in their central points. He is a co-author of the projects in Copenhagen, New York, London, Melbourne, Sydney. In Poland, he analyzed the structure of the city of Lodz, Poznan and Wroclaw) - world-renowned urban planner whose restoration and revitalization projects of urban fabric are aiming to shift the focus of communication - relieving traffic by giving the space for pedestrians and cyclists.

Copenhagen is considered to be one of his most successful realization, where currently up to $37 \%$ of daily trips are made by bicycle [11]. A significant slowdown in the speed limit on the street of the Danish capital has made this city safe and friendly for cyclists. The main aim of the designer was to 'provide cyclists with a safe place in the public space'. Four-lane streets were transformed into two-lane, the rest of it was given to cyclists. A key requirement of the cyclist-friendly space is a comprehensive transport strategy that includes cyclists. Such a strategy must establish a network between the cycling infrastructure and, in its broadest sense, public transport (buses, trolleybuses, trams, taxis). The consequence of such assumptions is the necessity to create spaces where cyclists will be able to leave their bikes safely in order to use the public transport (transport hubs).

The increasing number of cyclists in the city reduces the number of accidents on the road. Therefore, municipalities get the signal that it is a solution worth investing in. Studies show that with the increase of infrastructure for 'active' participants, the number of bicycle accidents has strongly decreased. It is caused not only due to the separation of car and bicycle routes, but also the increasing awareness of motorists and reduced speed limits in the city. Figure 2 shows the effect on the number of accidents that is entailed by the presence of bicycle paths.

In response to the increasing bicycle traffic in the city, the authorities for several years have consequently invested in the development of urban bike rental system. Not only does it promote the city, provide an opportunity to the efficient mobility, but also make a sizable profit. Every year the major Polish cities create new bike-stations, and as a consequence the number of users growth. The citizens' initiative - participatory budget (Participatory budgeting is a separate part of the budget of the local government (city or town) for the implementation of initiatives reported in direct elections by the local community [12]) shows that the idea has adopted. Among the ideas proposed citizens next stations and bike paths appear. 


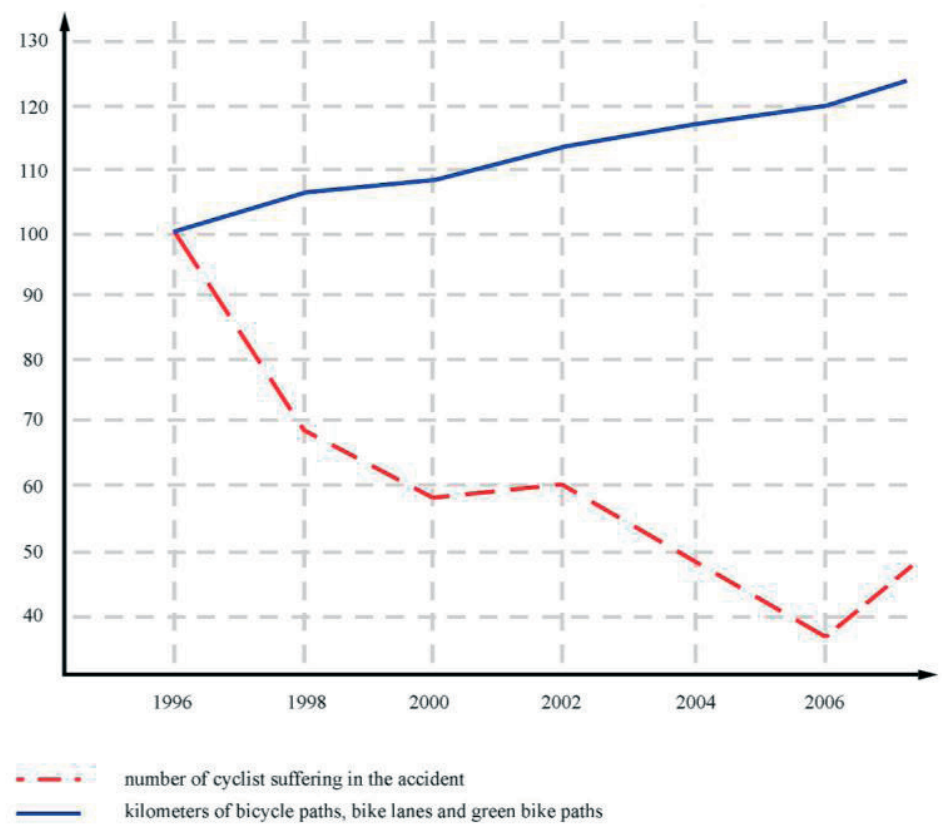

Fig. 2. The relationship between the cycling infrastructure and the number of bicycle accidents, on the basis of: J. Gehl 'Cities for people' Publisher RAM, I issue, Krakow 2014, p. 186, own elaboration

\section{Examples of properly designed solutions for cyclists}

There are many possible ways of signing cycle spaces. Below are presented some of them:

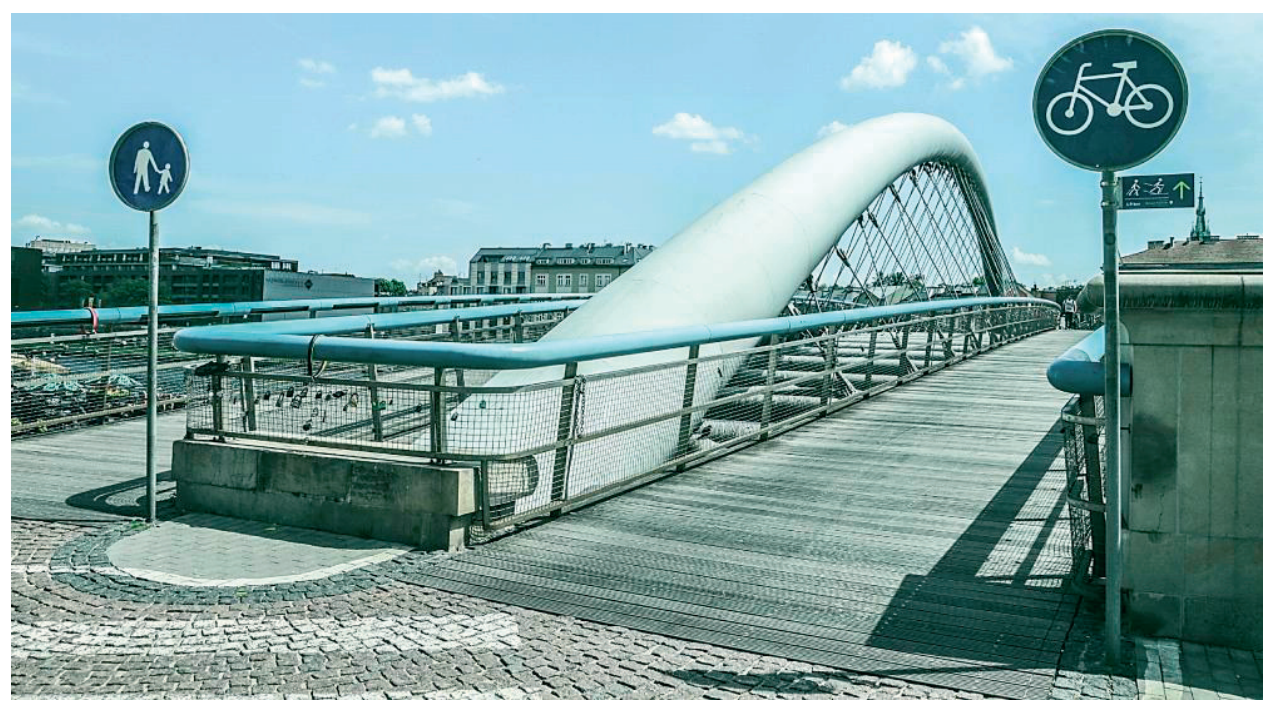

Fig. 3. Bike path on the Vistula river in Krakow (Poland) connecting the districts of Podgórze and Kazimierz. The solution completely separates bicycle traffic from pedestrians. Photo: Katarzyna Szmygin 

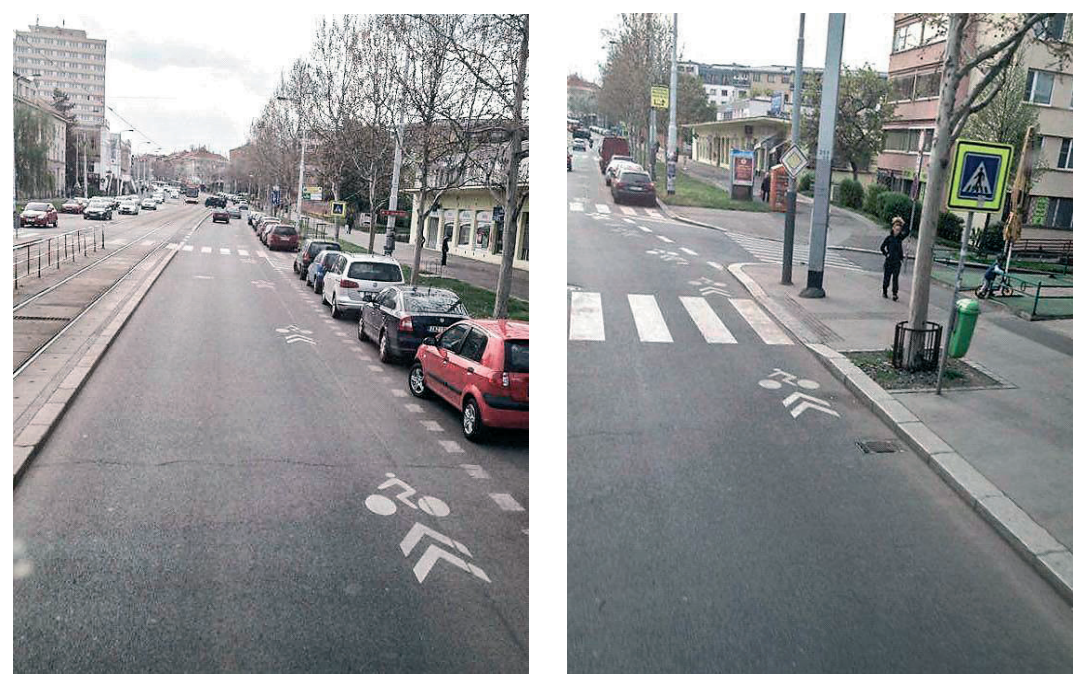

Fig. 4. Bike path on the street, Prague, Czech Republic. Photos: Katarzyna Szmygin

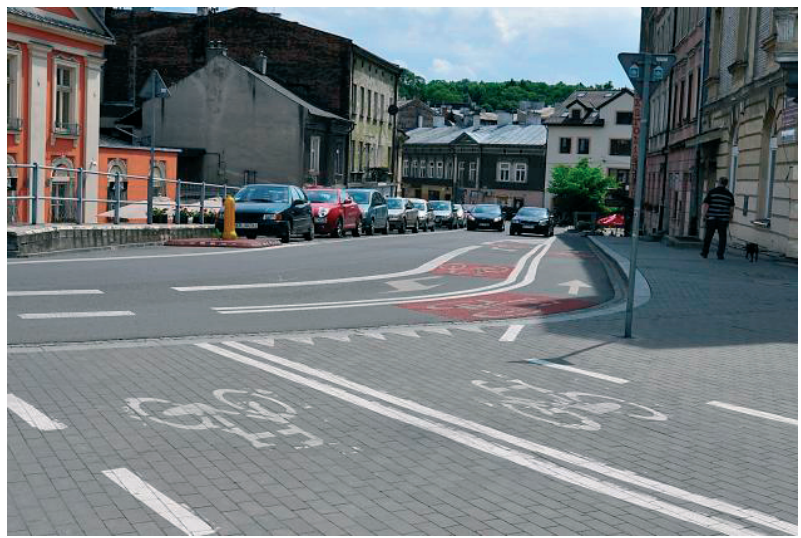

Fig. 5. Two-lane bike path, Krakow, Poland. Photo: Katarzyna Szmygin

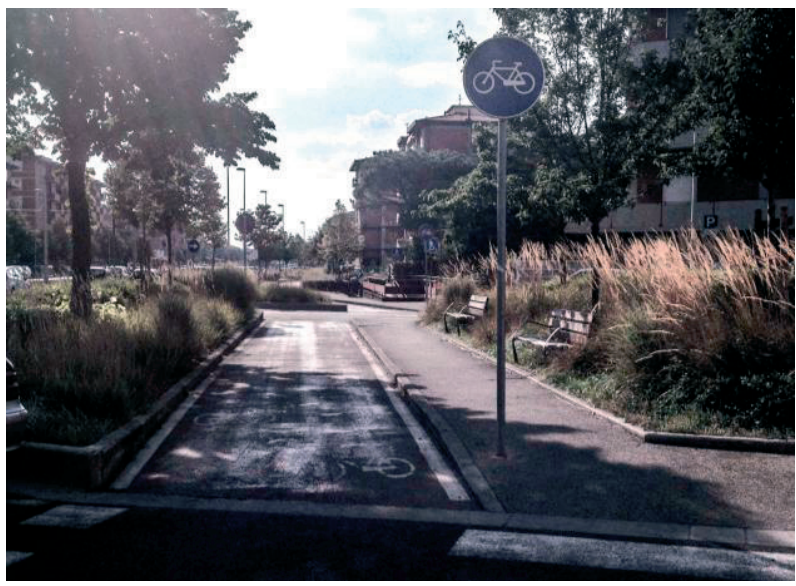

Fig. 6. Bike path, separated from the pedestrian one, Florence, Italy Photo: Katarzyna Szmygin 


\section{Conclusions}

Cyclists are an ever growing group of users of urban spaces. Polish legislation still requires more regulations, which in the future will help them move around the safe and collision-free city. The city authorities create more and more opportunities for cyclists, however, cyclists still are not treated as a priority group. Prognosis for the future give hope that this situation will change over the next few years and Poland will be able to compete with developed countries of Western Europe.

\section{References}

1. http://rankingi24.pl/motoryzacja/624-10-panstw-z-najwieksza-iloscia-samochodow-na-1000mieszkancow.html

2. Road Traffic Law of 20 June 1997.

3. http://archive.is/7DwVI

4. http://wrower.pl/miasto/dlugosci-sciezek-rowerowych-w-polskich-miastach,2044.html

5. Regulation of the Minister of Infrastructure and Maritime Economy of 2 March 1999 on the technical conditions for public roads and their location Journal of Laws No. 43.

6. Ibidem $\$ 47.1$

7. Ibidem $\S 48.1-2$

8. Journal of Laws No. 170 pos. 1393.

9. Journal of Laws No. 220 pos. 2181.

10. Detailed specifications for signs and signals and road traffic safety equipment and conditions for placing them on the road. Journal of Laws No. 220 pos. 2181.

11. Gehl J. Miasta dla ludzi. Publishing RAM, I issue, Krakow 2014, p. 182.

12. Kębłowski W. Budżet partycypacyjny. Krótka instrukcja obsługi. Warsaw 2013. 